\title{
EFFECT OF CALCIUM CHLORIDE TREATMENT ON HYBRIDOMA CELL VIABILITY AND GROWTH
}

\author{
Gyun Min Lee*, Bong Kwan Han, Jung Hoe Kim, and Bernhard O. Palsson ${ }^{1}$ \\ Department of Biotechnology, Korea Advanced Institute of Science \& Technology, \\ Kuseong-Dong, Yuseong-Gu, Taejun 305-701, Korea \\ and \\ 'Department of Chemical Engineering, University of Michigan, \\ Herbert H. Dow Building, Ann Arbor, MI 48109
}

\begin{abstract}
In order to minimize hybridoma cell damage during calcium alginate entrapment, the effect of calcium chloride treatment on hybridoma cell viability and growth was studied in terms of calcium chloride concentration and treatment time. The cell viability as measured by trypan blue exclusion did not decrease rapidly during the first hour of calcium chloride treatment regardless of calcium chloride concentrations used (1.3 and $1.5 \%)$. However, $1.3 \%$ calcium chloride solution appeared to be more detrimental to the cells than $1.5 \%$ calcium chloride solution. The cells in $1.3 \%$ calcium chloride solution lost their viability faster than the cells in $1.5 \%$ calcium chloride solution. In addition, when the cells treated with calcium chloride were inoculated into spinner flasks containing IMDM with $10 \%$ fetal calf serum, the cells treated with $1.3 \%$ calcium chloride solution showed a longer lag phase than the cells treated with $1.5 \%$ calcium chloride solution.
\end{abstract}

\section{INTRODUCTION}

The entrapment of hybridoma cells either into calcium alginate beads or into poly-1-lysine (PLL) alginate microcapsules has attracted considerable interest because entrapped cell cultures offer several advantages over conventional suspension cultures (Poscillio, 1986; Nilsson, 1987; Shirai et al., 1987; Tyo and Spier, 1987; Lim, 1988; Sinacore et al., 1989; Lee and Palsson 1990; Lee et al., 1991).

In alginate-entrapped cell cultures, much effort has been made to improve volumetric monoclonal antibody (MAb) productivity by either increasing the cell density and/or the cell specific MAb productivity. In contrast, few studies have been aimed at improving the process of hybridoma cell entrapment in calcium alginate beads. This optimization has been overlooked due to the apparent simplicity and gentle nature of the entrapment process. However, when calcium-alginate entrapped hybridoma cells were cultivated, cell viability often decreased at the beginning of culture, resulting in a prolonged lag phase (Lee et al., 1991; Wohlpart et al., 1991). This phenomenon may result from cell damage during the entrapment process and may be avoided by improving the entrapment process.

The entrapment of the cells in calcium alginate beads is achieved by dropping a mixture of sodium alginate and cells into a cold calcium chloride solution. The cells continue to experience calcium chloride 
during the bead formation process. Thus, the entrapped cells are exposed to calcium chloride solution for prolonged time periods. However, the effect of calcium chloride treatment which may have an adverse effect on the cells has not been well characterized (Spiekermann et al., 1987). Different concentrations of calcium chloride solution have been used, and different incubation time of the cells in calcium chloride solution have been used (King et al., 1987; Shirai et al., 1987; Lim, 1988; Lee et al., 1991; Wohlpart et al., 1991).

In this article, the effect of calcium chloride treatment on hybridoma cell (S3H5//2bA2) viability and growth is characterized in terms of calcium chloride concentration and treatment time. In addition, the effect of calcium chloride treatment on specific MAb productivity is also characterized.

\section{MATERIALS AND METHODS}

Cell line, medium, and culture maintenance Two murine hybridoma cell lines were used in this study. One cell line was $\$ 3 \mathrm{H} 5 / \gamma 2 \mathrm{bA} 2$ provided by Dr. Mark Kaminski from the University of the Michigan Medical Center. The antibody produced by this cell line is $\mathrm{IgG}_{2} \mathrm{~b}$ anti-idiotype antibody, directed against a carcinogen-induced B cell tumor (38C13) (Bergman and Haimovich, 1977). The fusion partner used was P3/x63/Ag8.653. The other cell line was S3H5/NP. This cell line lost its antibody productivity, and was originally derived from $S 3 H 5 / 2 \mathrm{bA} 2$ (Lee and Palsson, 1990).

The medium for culture maintenance was Iscove's modified Dulbecco's medium (IMDM, Gibco Laboratories, Grand Island, NY) supplemented with $10 \%(v / v)$ fetal bovine serum (FBS, Gibco Laboratories, Grand). No antibiotics were added to the medium. The cells were maintained in $25 \mathrm{~cm}^{2} \mathrm{~T}$-flasks (Bellco Glass, Inc., Vineland, $\mathrm{NJ}$ ) in a $5 \% \mathrm{CO}_{2}$ /air mixture, humidified at $37^{\circ} \mathrm{C}$. The cells were diluted $1: 5$ with fresh medium every other day.

Calcium chloride treatment, cell viability, and cell growth Two different concentrations of calcium chloride solution (Sigma, St. Louis, MO) were prepared. A $1.3 \%$ calcium chloride solution buffered with $13 \mathrm{mM}$ HEPES (Sigma) was prepared as described by Lim (1988), and a $1.5 \%$ calcium chloride solution was prepared by King et al. (1987). Osmolarities of $1.3 \%$ and $1.5 \%$ calcium chloride solutions measured using an Osmometer (Osmette, model 2007, Precision systems, Inc., Natick, MA) were 322 and $346 \mathrm{mOsm}$, respectively.

The effect of calcium chloride on cell viability was studied as follows: Exponentially growing cells (cell density $\approx 2.0 \times 10^{6} \mathrm{cell} / \mathrm{s} / \mathrm{ml}$ ) were centrifuged at $1000 \mathrm{~mm}$ for $10 \mathrm{~min}$. After discarding the supernatant, cells were resuspended in two different concentrations of calcium chloride solution $\left(4^{\circ} \mathrm{C}\right)$, respectively, and then were kept in an ice bath. Viable cell concentration was monitored as a function of calcium chloride treatment time by the trypan blue dye exclusion method. When the trypan blue in phosphate buffer was used, precipitation of calcium ions with phosphate ions made it difficult to distinguish viable cells from dead cells (Shirai and Hashimoto, 1989). Thus, a $4 \%(\mathrm{w} / \mathrm{v})$ trypan blue in an $0.85 \% \mathrm{NaCl}$ solution (pH 7.4) was used to avoid precipitation.

The effect of calcium chloride treatment on cell growth was studied as follows: After incubating the celis in calcium chloride solution at $4^{\circ} \mathrm{C}$ as previously described, the cells were centrifuged at $1000 \mathrm{rpm}$ for $10 \mathrm{~min}$. The time required for centrifugation was also included for calculating the incubation time of the cells in calcium chloride solution. After discarding the supernatant, the cells were resuspended in IMDM supplemented with 10\% FBS, and then were centrifuged again. After discarding the supernatant, the cells were resuspended in IMDM with 10\% FBS. The cells were inoculated into the spinner flasks (Bellco Glass, Inc.) containing $50 \mathrm{ml}$ of IMDM with $10 \%$ FBS at various initial cell concentrations. The agitation speed used in the spinner flasks was $100 \mathrm{rpm}$. The cultures were kept at $37^{\circ} \mathrm{C}$ in a humidified $\mathrm{CO}_{2}$ incubator (VWR Scientific, San Fransisco, CA).

Analytical methods The cell culture suspension was centrifuged. The supernatant was aliquoted and kept frozen at $-80^{\circ} \mathrm{C}$. The total secreted antibody, $\operatorname{IgG}_{2} \mathrm{~b}$, was quantified using an enzyme linked immunosorbent assay (ELISA) as described previously (Lee et al., 1989).

The specific growth rate and specific MAb production rate were evaluated as described earlier (Lee et al., 1989). 

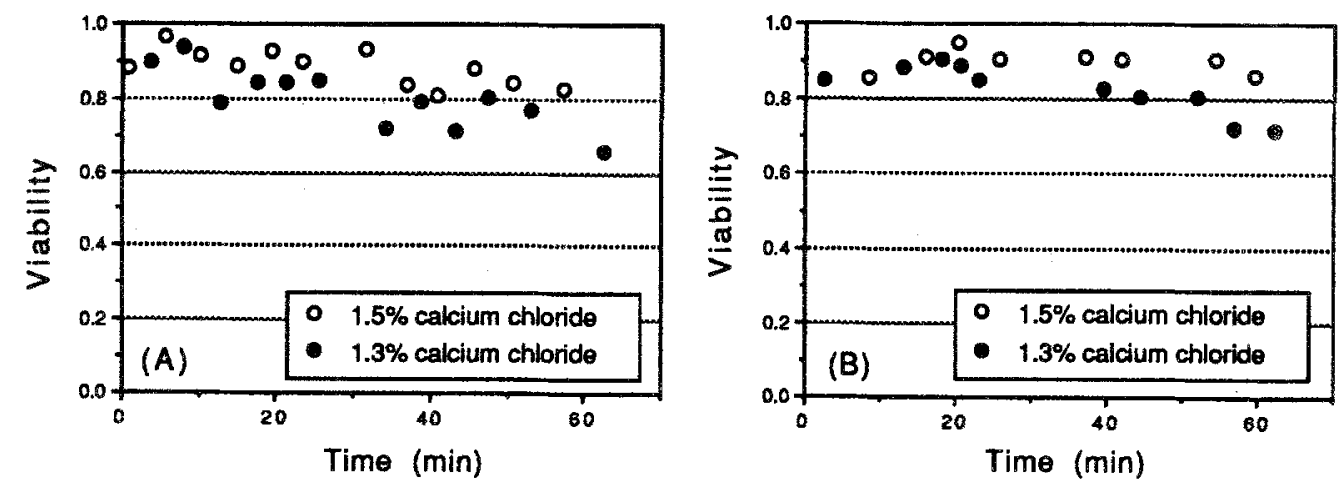

Figure 1. Cell viability versus calcium chloride treatment time: (a) $S 3 H 5 / / 2 b A 2$ (b) $S 3 H 5 / N P$

\section{RESULTS AND DISCUSSION}

In order to investigate the effect of calcium chloride treatment on cell viability, the cells were incubated in different concentrations of calcium chloride solution. The calcium alginate concentrations used were $1.3 \%$ and $1.5 \%$, since both have been widely used for entrapping hybridoma cells into calcium alginate beads. The cell viability was plotted as a function of the calcium chloride treatment time (Fig. 1). Since total cell concentration did not decrease during calcium chloride treatment, the cell viability directly indicates the changes in viable cell concentration. Although the cell viability did not decrease rapidly during calcium chloride treatment regardless of calcium chloride concentrations, the cells in $1.3 \%$ calcium chloride solution appeared to lose their viability faster than the cells in $1.5 \%$ calcium chloride solution. The reason for this result might be due to the difference in osmolarities of calcium chloride solutions. Assuming that the decrease in the cell viability follows the first order kinetics with respect to calcium chloride treatment time, the viability decay rate constant $\left(\mathrm{min}^{-1}\right), k$, was determined as described by Aiba et al. (1973). For $\mathrm{S} 3 \mathrm{H} 5 / \mathrm{\gamma} 2 \mathrm{bA} 2$ cells, the values of $k$ in $1.3 \%$ and $1.5 \%$ calcium chloride solution were approximately 0.0043 and $0.0020 \mathrm{~min}^{-1}$, respectively. For S3H5/NP cells, the values of $k$ in $1.3 \%$ and $1.5 \%$ calcium chloride solution were approximately 0.0034 and $0.0003 \mathrm{~min}^{-1}$, respectively. Accordingly, if the cells ( $\mathrm{S} 3 \mathrm{H} 5 / \gamma 2 \mathrm{bA} 2$ ) are exposed to $1.5 \%$ calcium chloride solution for less than an hour during the immobilization process, the loss of cell viability by detrimental effect of calcium chloride solution would be less than $12 \%$ of an initial viable cell concentration.

However, cell viability was estimated by trypan blue dye exclusion method which relies on a breakdown in membrane integrity determined by the uptake of trypan blue. Dye exclusion method tends to overestimate viability (Freshney, 1987). Thus, the observation that the cells in calcium chloride solution did not lose their viability significantly does not necessarily mean that the cells were not damaged with respect to their growth ability and that the cells in $1.5 \%$ calcium chloride were less damaged than the cells in $1.3 \%$ calcium chloride solution. Therefore, the cffect of calcium chloride solution on cell growth ability ( $33 \mathrm{H} 5 / 2 \mathrm{bA} 2$ ) was investigated in terms of calcium chloride treatment time and concentration. 

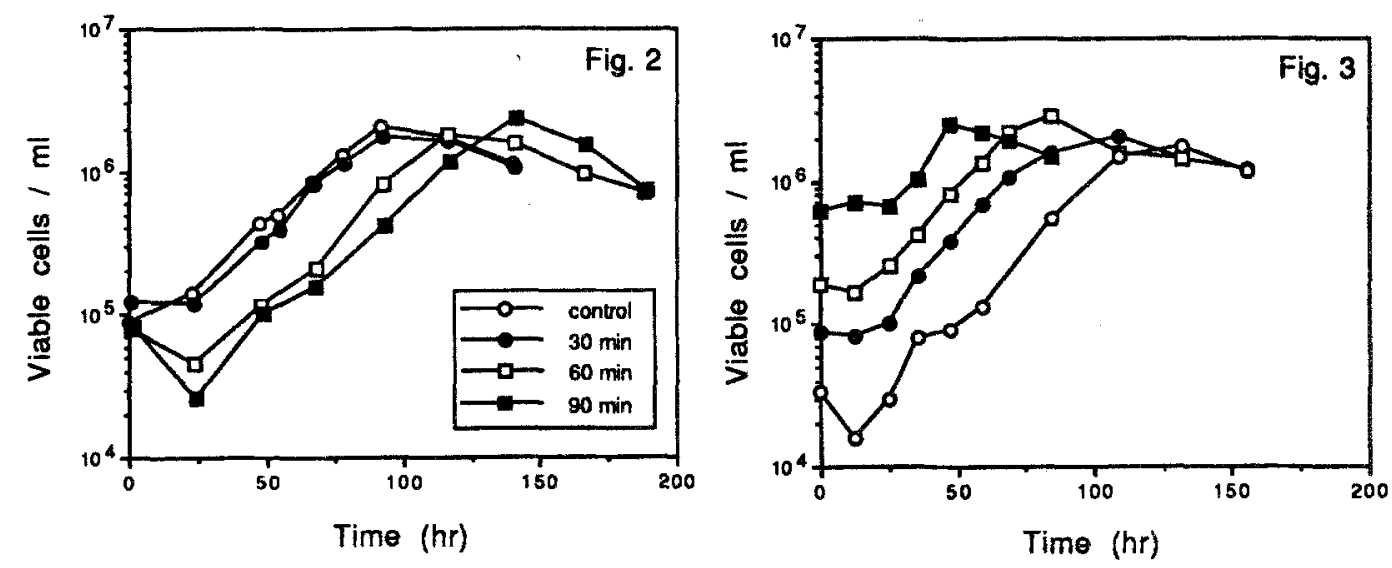

Figure 2. Growth curves of $S 3 H 5 / \gamma 2 \mathrm{bA} 2$ cells after varying exposure to $1.5 \%$ calcium chloride. Cells without calcium chloride treatment were used as a control. Different symbols indicate various calcium chloride treatment time.

Figure 3. Effect of initial cell concentration on growth of $\$ 3 H 5 / \gamma 2 \mathrm{bA} 2$ cells following 60 min exposure to $1.5 \%$ calcium chloride solution.

First, the cells which had been incubated in $1.5 \%$ calcium chloride solution with varying incubation times were inoculated into spinner flasks. As shown in Fig. 2, cell growth ability was affected by calcium chloride treatment. While the cells were incubated in calcium chloride solution, the cell growth ability deteriorated. Unlike the cells without calcium chloride treatment, the cells incubated in calcium chloride solution longer than an hour experienced one or two days of lag phase. Since the growth of $33 \mathrm{H} 5 / \mathrm{\gamma} 2 \mathrm{bA2}$ hybridoma cell was reported to be cell concentration-dependent (Lee et al., 1989), the lag phase induced by cell damage during calcium chloride treatment may be reduced by increasing the initial cell concentration. Thus, the cells which had been incubated in calcium chloride solution for an hour were inoculated into spinner flasks at various initial cell concentrations. As shown in Fig. 3, it was found that the duration of lag phase could not be shortened noticeably by increasing the initial cell density up to $6 \times 10^{5}$ cells/ml. Second, in order to investigate the effect of calcium chloride concentration on cell growth ability, the cells treated with $1.3 \%$ and $1.5 \%$ calcium chloride for an hour were inoculated into spinner flasks, respectively. The cells treated with $1.3 \%$ calcium chloride solution showed a longer lag phase than the cells treated with $1.5 \%$ calcium chloride solution, confirming the previous results that the cells in $1.3 \%$ calcium chloride solution lost their viability faster than the cells in $1.5 \%$ calcium chloride solution during calcium chloride treatment (Fig. 4). Accordingly, in order to minimize cell ( $33 \mathrm{H} 5 / / 2 \mathrm{bA} 2$ hybridoma) damage during calcium alginate entrapment, it is desirable to use a $1.5 \%$ calcium chloride solution rather than a $1.3 \%$ calcium chloride solution. In addition, an exposure time of the cells to a calcium chloride solution should be minimized. When a commercially available alginate, Keltone LV (Kelco, Chicago, IL), was used, an exposure time of the cells to a calcium chloride solution could be shortened to less than 30 min without 
weakening the mechanical strength of calcium alginate beads. The calcium alginate-entrapped cells did not show any significant lag phase and could be cultivated in a spinner flask for more than two weeks by keeping the integrity of calcium alginate beads (Lee et al., 1992).
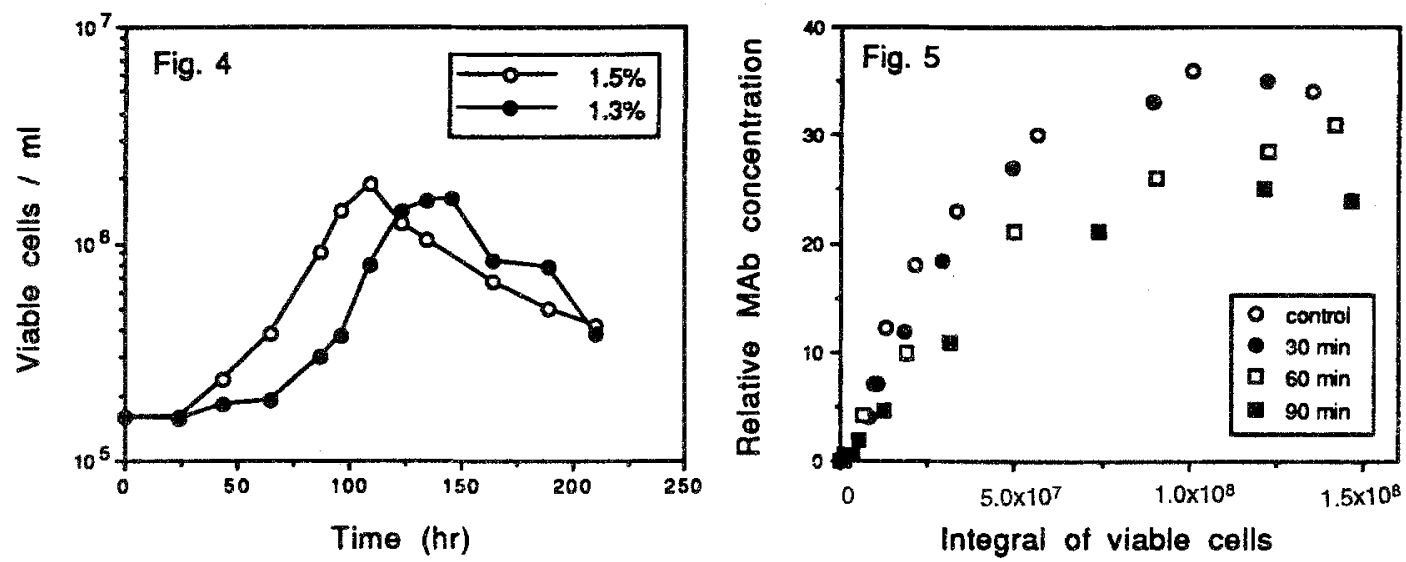

Figure 4. Effect of calcium chloride concentration on $S 3 H 5 / / 2 b A 2$ cell growth ability.

Figure 5. MAb concentrations versus integral of viable cell concentrations with respect to culture time. These data originated from the culture shown in Figure 2.

Specific MAb productivity of hybridoma cells often increased by environmental stresses (e.g., hyperosmolarity, pH shocks, and thawing and freezing of hybridoma cells) (Miller et al., 1988; Miller $e t$ al., 1988a; Berg et al., 1990; Hiller et al., 1991). Entrapped S3H5/Y2bA2 hybridoma cells in calcium alginate beads were observed to have enhanced specific MAb productivity for which calcium chloride treatment might be responsible (Lee et al., 1991). In order to test this hypothesis, specific MAb production rates of the cells with varying time of calcium chloride treatment were obtained by plotting MAb concentration versus the integral of viable cell concentration with respect to time during the cultures which correspond to Fig. 2. The slopes of curves indicate specific MAb production rates. As shown in Fig. 5 , the specific MAb production rate of cells treated with calcium chloride did not increase, and in fact deteriorated. Thus, the enhanced specific MAb production rate of calcium alginate entrapped cells was not due to calcium chloride treatment.

In conclusion, the cell viability did not decrease rapidly during one hour calcium chloride treatment, but the cell growth ability deteriorated. In addition, $1.3 \%$ calcium chloride solution appeared to be more detrimental to the cells than $1.5 \%$ calcium chloride solution. Thus, it is desirable to use $1.5 \%$ calcium chloride solution and to minimize the exposure time of the cells to calcium chloride solution.

Acknowledgments The authors thank Dr. Mark Kaminski for supplying the cell line. The authors also thank Jeff Gray and Sang Jick Kim for their technical assistance. This work was supported by National Science Foundation (BSC-9009389) and KAIST. 


\section{REFERENCES}

Aiba, S., Humphrey, A. E., and Mills, N. F. (1973) Biochemical Engineering, Tokyo: University of Tokyo Press.

Berg, T. M., $\Phi$ yass, K., and Levine, D. W. (1990). Growth and antibody production of hybridoma cells exposed to hyperosmotic stress. In: Trends in Animal Cell Culture Technology. Murakami, H. ed. pp. 93-97, Tokyo, Kodansha Ltd.

Bergman, Y., and Haimovich, J. (1977). Eur. J. Immunol., 7, 413-417.

Freshney, R. I. (1987). Culture of Animal Cells, New york: Alan R. Liss, Inc..

Hiller, G. W., Aeschlimann, A. D., Clark, D. S., and Blanch, H. W. (1991) Biotechnol. Bioeng. 38, 733741.

King, G. A., Daugulis, A. J., Faulkner, P., and Goosen, M. F. A. (1987). Biotechnol. Prog. 3, 231-240.

Lee, G. M., Huard, T. K., and Palsson, B. O. (1989). Hybridoma 8, 369-375.

Lee, G. M., and Palsson, B. O. (1990). Biotechnol. Bioeng. 36, 1049-1055.

Lee, G. M., Varma, A., and Palsson, B. O. (1991). Biotechnol. Bioeng. 38, 821-830.

Lee, G. M., Chuck, A., and Palsson, B. O. (1992). submitted for publication.

Lim, F. (1988) Microencapsulation of living mammalian cells. In: Upstream Processes:

Equipment and Techniques. Mizrahi, A. ed. pp. 185-197, New York: Alan R. Liss, Inc.

Miller, W. M., Blanch, H. W, and Wilke, C. R. (1988). Biotechnol. Bioeng. 32, 947-965.

Miller, W. M., Blanch, H. W, and Wilke, C. R. (1988a). J. Cell Physiol. 132, 524-530.

Nilsson, K. (1987). Trends Biotechnol. 5, 73-78.

Poscillico, E. G. (1986). Bio/Technol., 4, 114-117.

Shirai, Y., Hashimoto, K., Yamaji, H., and Tokashiki, M. (1987). Appl. Microbiol. Biotechnol. 26, 495499.

Shirai, Y., and Hashimoto, K. (1989). J. Ferment. Technol. 68, 264-268.

Sinacore, M. S., Creswick, B. C., and Buehler, R. (1989). BiolTechnol. 7, 1275-1279.

Spiekermann, P., Vorlop, K. D., and Klein, J. (1987). Proc. $4^{\text {th }}$ European Congress on Biotechnology. 3, 590-593.

Tyo, M. A., and Spier, R. E. (1987). Enzyme Microb. Technol. 9, 514-520.

Wohlpart, D., Gainer, J., and Kirwan, D. (1991). Biotechnol. Bioeng. 37, 1050-1053. 